\title{
Fretting wear of hydrogenated zirconium alloy E125, strengthened by diffusion coatings
}

\author{
I. N. Burnyshev ${ }^{1}$, D. G. Kalyuzhnyi ${ }^{\dagger, 1,2}$, V.F. Lys ${ }^{1}$, V. V. Tarasov ${ }^{1}$, V. A. Fukalov ${ }^{1}$ \\ †dikdik@mail.ru
}

${ }^{1}$ Udmurt Federal Research Center of the UB RAS, Izhevsk, 426067, Russia

${ }^{2}$ Kalashnikov Izhevsk State Technical University, Izhevsk, 426069, Russia

\begin{abstract}
Protective coatings that improve the corrosion resistance of the E125 zirconium alloy under conditions of the combined effect of a hydrogen-containing medium and friction wear have been investigated. The formation of coatings on the surface of the samples was carried out by thermal diffusion treatment in powder saturating media with halogen activation at temperatures from $400^{\circ} \mathrm{C}$ to $950^{\circ} \mathrm{C}$. The resulting coatings were formed as a result of the processes of oxidation, siliconization, and nitrocarburizing. Wear tests were carried out on a SRV Testsystem multifunctional testing system according to the disk-ball scheme without lubrication. Cathodic hydrogenation of the samples was carried out in an electrolyte solution containing a single normal sulfuric acid solution at room temperature. The cathodic current density was from 20 to $500 \mathrm{~mA} / \mathrm{cm}^{2}$. The hydrogen concentration in the samples was determined on a highly sensitive G8 Galileo $\mathrm{H}$ gas analyzer by melting the samples in a carrier gas flow. As a result of the study, it was shown that the wear of the coated specimens after siliconizing and nitrocarburizing is three times lower than that of the original uncoated specimen. Oxidation leads to a significant, more than fivefold, increase in the amount of wear, in comparison with the same initial sample. Hydrogenation of the surface of the samples allows not only to reduce the coefficient of friction, but also to reduce the amount of wear in the process of testing samples for fretting wear. This study makes it possible to obtain modified surfaces of zirconium samples that significantly improve the mechanical properties, as well as reduce the level of hydrogenation, and increase the performance of components made of zirconium alloys under conditions of increased friction.
\end{abstract}

Keywords: coatings, fretting, wear, zirconium, hydrogen.

\section{Фреттинг-изнашивание наводороженного циркониевого сплава Э125, упрочненного диффузионными покрытиями}

\author{
Бурнышев И. Н. ${ }^{1}$, Калюжный Д. Г. ${ }^{\dagger, 1,2}$, Лыс В. Ф. ${ }^{1}$, Тарасов В. В. ${ }^{1}$, Фукалов В. А. ${ }^{1}$ \\ ${ }^{1}$ Удмуртский федеральный исследовательский центр УО РАН, Ижевск, 426067, Россия \\ ${ }^{2}$ Ижевский государственный технический университет им. М. Т. Калашникова, Ижевск, 426069, Россия
}

Исследованы защитные покрытия, улучшающие коррозионную стойкость циркониевого сплава Э125 в условиях совместного влияния водородосодержащей среды и изнашивания трением. Формирование покрытий на поверхности образцов осуществлялось термодиффузионной обработкой в порошковых насыщающих средах с галоидной активацией при температурах от $400^{\circ} \mathrm{C}$ до $950^{\circ} \mathrm{C}$. Полученные покрытия образовывались в результате процессов оксидирования, силицирования и азотонауглероживания. Испытания по изнашиванию проводили на многофункциональной испытательной системе SRV Testsystem по схеме диск-шарик без смазки. Катодное наводороживание образцов проводили в растворе электролита, содержащем однонормальный раствор серной кислоты, при комнатной температуре. Плотность катодного тока составляла от 20 до 500 мА/см². Концентрацию водорода в образцах определяли на высокочувствительном газоанализаторе G8 Galileo Н методом расплавления образцов в потоке несущего газа. В результате исследования показано, что износ образцов с покрытиями после силицирования и азотонауглероживания снижается в три раза, по сравнению с исходным образцом без покрытия. Оксидирование приводит к существенному, более чем в пять раз, росту величины износа, в сравнении с тем же исходным образцом. Наводороживание поверхности образцов позволяет не только снизить коэффициент трения, 
но и уменьшить величины износа в процессе испытаний образцов на фреттинг-изнашивание. Это исследование позволяет получать модифицированные поверхности циркониевых образцов, существенно улучшающие механические свойства, а также снизить уровень наводороживания, и повысить работоспособность компонентов, выполненных из циркониевых сплавов, в условиях повышенного трения.

Ключевые слова: покрытия, фреттинг, изнашивание, цирконий, водород.

\section{1. Введение}

Одним из способов повышения надежности работы атомных реакторов является нанесения покрытий на оболочки твэлов, которые позволяют эффективно защищать металл труб тепловыделяющих элементов от высокотемпературной коррозии, наводороживания и фреттинг-изнашивания как в условиях эксплуатации реактора, так и при аварийных ситуациях $[1,2]$. В работах [3-8] для улучшения коррозионных и трибологических свойств на циркониевые оболочки наносили покрытия из нитрида титана $\mathrm{TiN}$ и нитрида хрома CrN. В числе возможных кандидатных сплавов для покрытий, предотвращающих высокотемпературную коррозию в паре, рассматриваются фазы $\mathrm{Ti}_{3} \mathrm{SiC}_{2}$ и $\mathrm{Ti}_{3} \mathrm{AlC}_{2}$, наносимые на циркониевые сплавы термическим или холодным напылением [9-10]. Такие покрытия являются диффузионным барьером для водорода, апоизносостойкостизначительнопревосходятподложку Zry-4. Привлекательным материалом для покрытий на сплавах циркония является металлический хром из-за высокой температуры плавления, хорошей стойкостью к высокотемпературному окислению, износостойкостью и близких значений коэффициентов теплового расширения хрома и циркония [11]. В циркалое-4 с нанесенного магнетронным распылением слоем $\mathrm{Cr}$ толщиной 10 мкм после 200-часовых испытаний при $415^{\circ} \mathrm{C}$ содержание водорода составило $25 \mathrm{ppm}$, а в сплаве без покрытия 1000 ррm; прирост массы составил соответственно 5 и 260 мг/дм² [12]. На сплаве с Cr-покрытием, полученным по 3D лазерной технологии, увеличение массы образцов при $1200^{\circ} \mathrm{C}$ было в 25 раз меньше, чем у образцов без покрытия [13]. Высокими защитными свойствами против высокотемпературной коррозии, износа и наводороживаемости характеризуются оксидные покрытия, формируемые на сплавах микродуговым оксидированием [14-15], атомно-слоевого осаждения [16] и вакуумно-дуговым плазменноассистированным методом [17]. В качестве перспективных покрытий для циркониевых сплавов в работе [18] рассматриваются силициды $\mathrm{ZrSi}_{2}$, наносимые на сплав магнетронным напылением.

Рассмотренные покрытия в основном наносятся на подложку такими методами как физическим или химическим осаждением из пара, вакуумно-дуговым напылением, плазменным напылением с последующим лазерным сканированием, 3D-лазерной технологией и холодным напылением. Для повышения эксплуатационных свойств изделий из металлов и сплавов достаточно широко применяется термодиффузионная обработка. Работы по применению термодиффузионной обработки для упрочнения циркониевых сплавов прак- тически отсутствуют. Целью данной работы является исследование совместного влияния наводороживания и термодиффузионной обработки на износостойкость циркониевого сплава Э125, широко применяемого в атомной и химической промышленности.

\section{2. Материалы и методика проведения экспериментов}

В качестве объекта исследования использовали образцы размерами $25 \times 25 \times 2$ мм, вырезанные из листа циркониевого сплава Э125 (химический состав сплава в процентах: $0.003 \mathrm{Ni}$; $0.0056 \mathrm{C} ; 0.0035 \mathrm{Fe} ; 0.05 \mathrm{O}_{2} ; 0.003 \mathrm{Al}$; $0.003 \mathrm{Ti} ; 0.0319$ другие примеси; $2.6 \mathrm{Nb}$; остальное $\mathrm{Zr}$ ). Для удаления оксидной пленки образцы перед началом эксперимента подвергались 30-секундному травлению при комнатной температуре в 5\%-ном растворе плавиковой кислоты.

Изнашивание проводили на многофункциональной испытательной системе SRV Testsystem по схеме дискшарик без смазки. Материал шарика (контробразца) инструментальная сталь ШХ15 после соответствующей упрочняющей термической обработки. В проведенных испытаниях на фреттинг-изнашивание амплитуда колебаний составляла 1.5 мм при частоте колебаний 10 Гц, нагрузка на образец 10 Н. Длительность испытаний составляла 10 мин.

Катодное наводороживание образцов проводили при температуре $(20 \pm 2)^{\circ} \mathrm{C}$ в однонормальном растворе серной кислоты, с добавлением 1.5 г тиокарбамида $\mathrm{CS}\left(\mathrm{NH}_{2}\right)_{2}$ на 1 литр раствора. Плотность катодного тока варьировалась от 20 до $500 \mathrm{MA} / \mathrm{cm}^{2}$. Для наводороживания применяли электролитическую ячейку, схема которой приведена в работе [13]. Концентрацию водорода в образцах определяли на высокочувствительном газоанализаторе G8 Galileo Н методом расплавления образцов в потоке несущего газа (аргон высокой чистоты).

Термодиффузионная обработка проводилась в порошковых насыщающих средах с галоидной активацией [13]. Температура обработки варьировалась в зависимости от типа насыщающего элемента от $400^{\circ} \mathrm{C}$ до $950^{\circ} \mathrm{C}$.

Микроструктуру образцов после наводороживания и термодиффузионной обработки исследовали на металлографиическом микроскопе NEOFOT-32. Фазовый состав определяли с помощью рентгеновских дифрактометров ДРОН-6 и D2 PHASER.

\section{3. Результаты и обсуждение}

При испытании на фреттинг-изнашивание, для образца в исходном состоянии (Рис. 1) наблюдается равномерный 


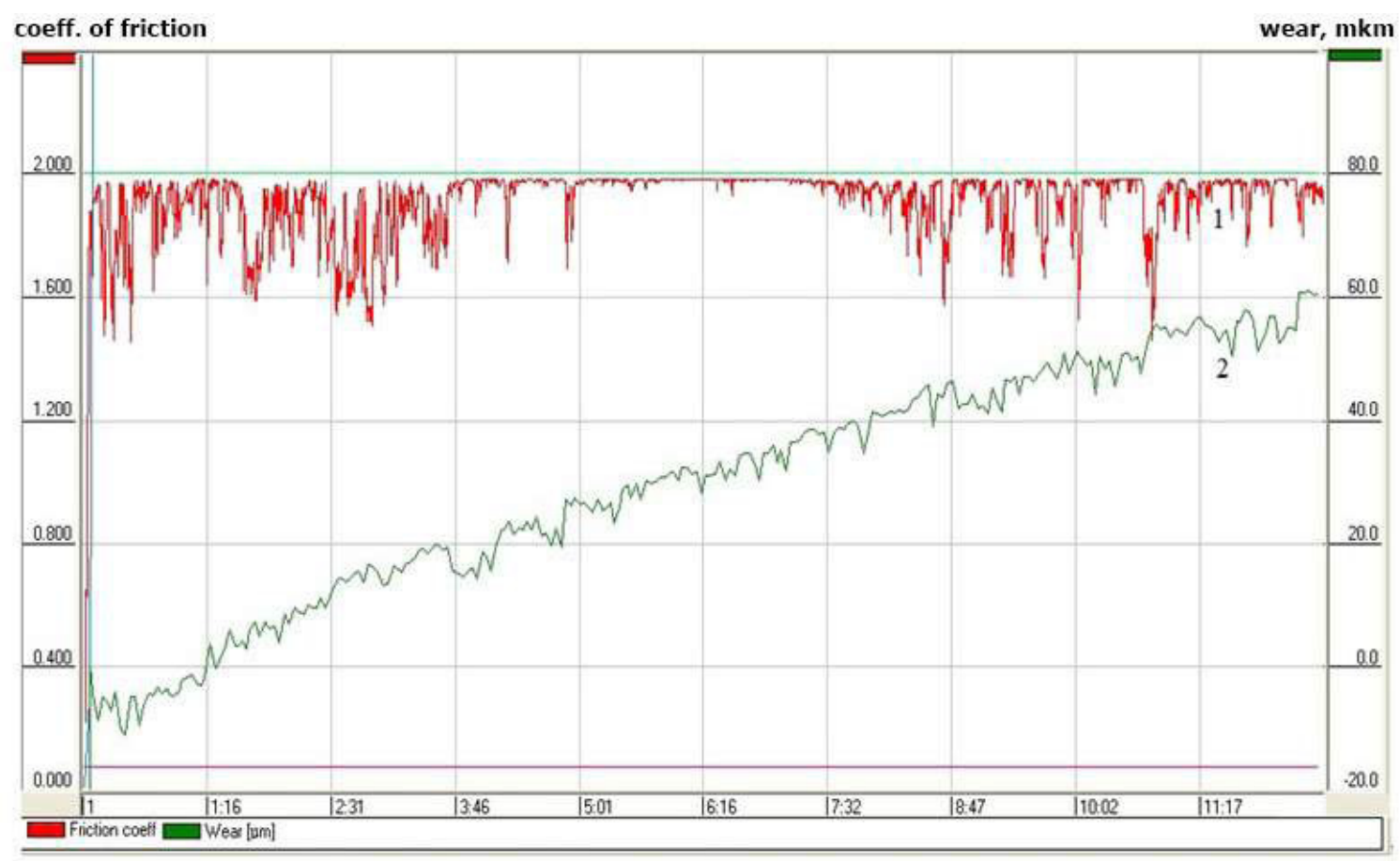

Pис. 1. (Color online) Трибограмма образца в исходном состоянии: $1-$ коэффициент трения, $2-$ износ.

Fig. 1. (Color online) Tribogram of the sample in the initial state: 1 - coefficient of friction, $2-$ wear.

износ на протяжении всего времени испытания. Максимальный износ составляет 60 мкм.

Для наводоженного образца без нанесенного покрытия наблюдается снижение коэффициента трения в первые минуты изнашивания, что вызвано попаданием продуктов изнашивания в зону контакта. Общий износ образца после наводороживания составляет 40 мкм, что ниже на 20 мкм, чем значение для образца в исходном состоянии. Коэффициент трения остается на том же уровне.

После нанесения защитных покрытий, образцы так же были подвергнуты испытаниям на фреттинг-изнашивание, для оценки величины и изменения коэффициента трения в процессе испытания и величины износа покрытия. Помимо этого, образцы с покрытиями были наводорожены, после чего были проведены повторные испытания. По результатам испытаний были построены трибограммы для каждого из образцов.

На трибограмме образца после азотонауглероживания (Рис. 2) наблюдается износ образца в два этапа (кривая 2), первый - с начала проведения испытаний и до 3 мин, второй - с 3 мин и до окончания проведения испытаний (10 мин). Максимальный износ образца составил 20 мкм. До 3 мин происходит резкий рост коэффициента (кривая 1) трения с 0.2 до 1.3, после трех минут испытаний коэффициент трения выходит на постоянную величину 0.8 .

Для образца, после оксидирования (Рис. 3), наблюдается резкий рост коэффициента трения и величины износа уже с начала процесса фреттинг-изнашивания. Данное обстоятельство объясняется сильным окислением образца. Максимальный износ образца составил 320 мкм.
Оксидная пленка на поверхности циркония, которая образуется при недостатке кислорода, обладает высокой твердостью и защитными свойствами. Однако в случае фреттинг-коррозии износ будет значительным при превышении критической частоты вибрации, когда оксидная пленка не успевает образовываться в период между проходами. Оценка критической частоты составляет 10 Гц и выше.

На трибограмме образца после силицирования (Рис. 4) наблюдается стабильный рост износа и коэффициента трения на протяжении всего эксперимента. Максимальный износ образца составил 17 мкм. Значение коэффициента трения к концу испытаний достигает максимального значения 0.9.

Помимо фреттинг-изнашивания образцов после нанесения покрытий были проведены аналогичные испытания на этих же образцах после наводороживания поверхности при плотности тока $100 \mathrm{~mA} / \mathrm{cm}^{2}$ в течение 8 часов.

Наводороживание образца с азотонауглероженной поверхностью (Рис. 5) привело к снижению коэффициента терния во время изнашивания до значения 0.25 . Максимальный износ образца составил 5 мкм, что значительно ниже, чем значение износа до наводороживания.

Для образца оксидированного и наводороженного, получены аналогичные результаты. По сравнению с этим же образцом без наводороживания наблюдается резкое, более чем в четыре раза, снижение износа до 75 мкм. И снижение коэффициента трения до значения 1.4.

Наводороживание образца после силицирования не оказывает существенного влияния на процесс изнашивания. Коэффициент трения и износ сохраняются на прежнем уровне. 
coeff. of friction

wear, mkm

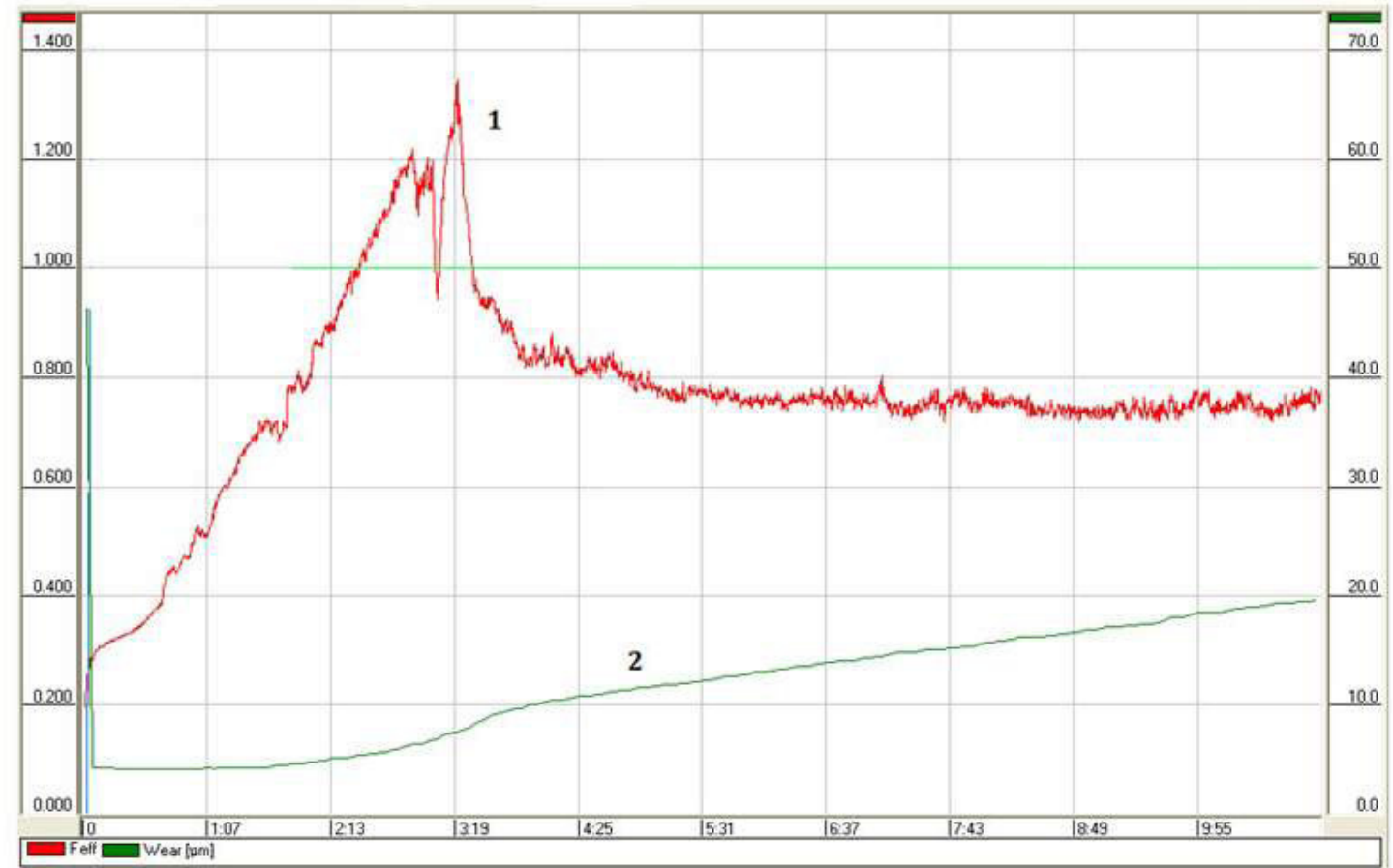

Pис. 2. (Color online) Трибограмма образца после азотонауглероживания: 1 - коэффициент трения, 2 - износ.

Fig. 2. (Color online) Tribogram of sample after nitrocarburizing: 1 - coefficient of friction, 2 - wear.

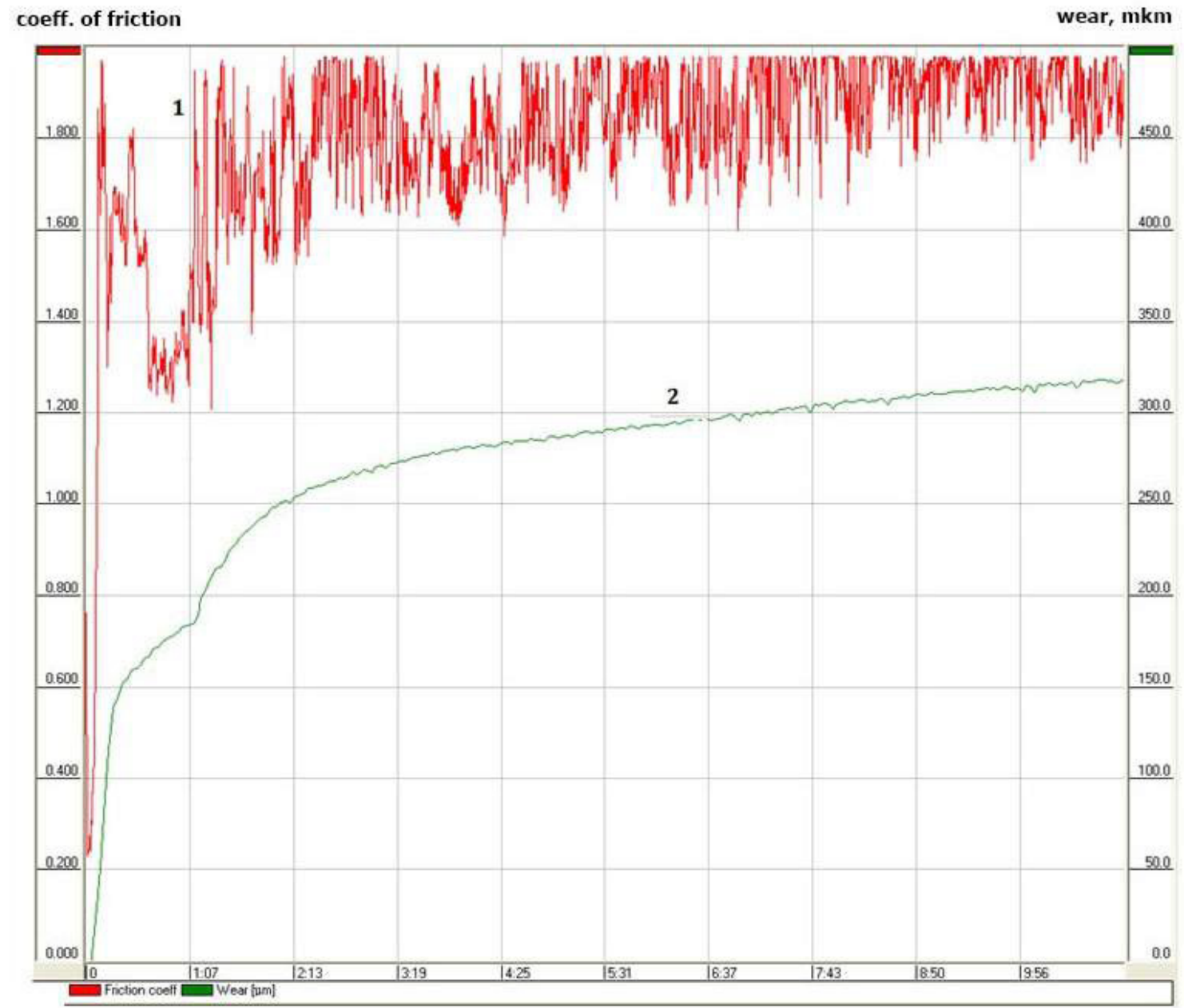

Pис. 3. (Color online) Трибограмма образца после оксидирования: 1 - коэффициент трения, 2 - износ.

Fig. 3. (Color online) Tribogram of sample after oxidation: 1 - coefficient of friction, $2-$ wear. 


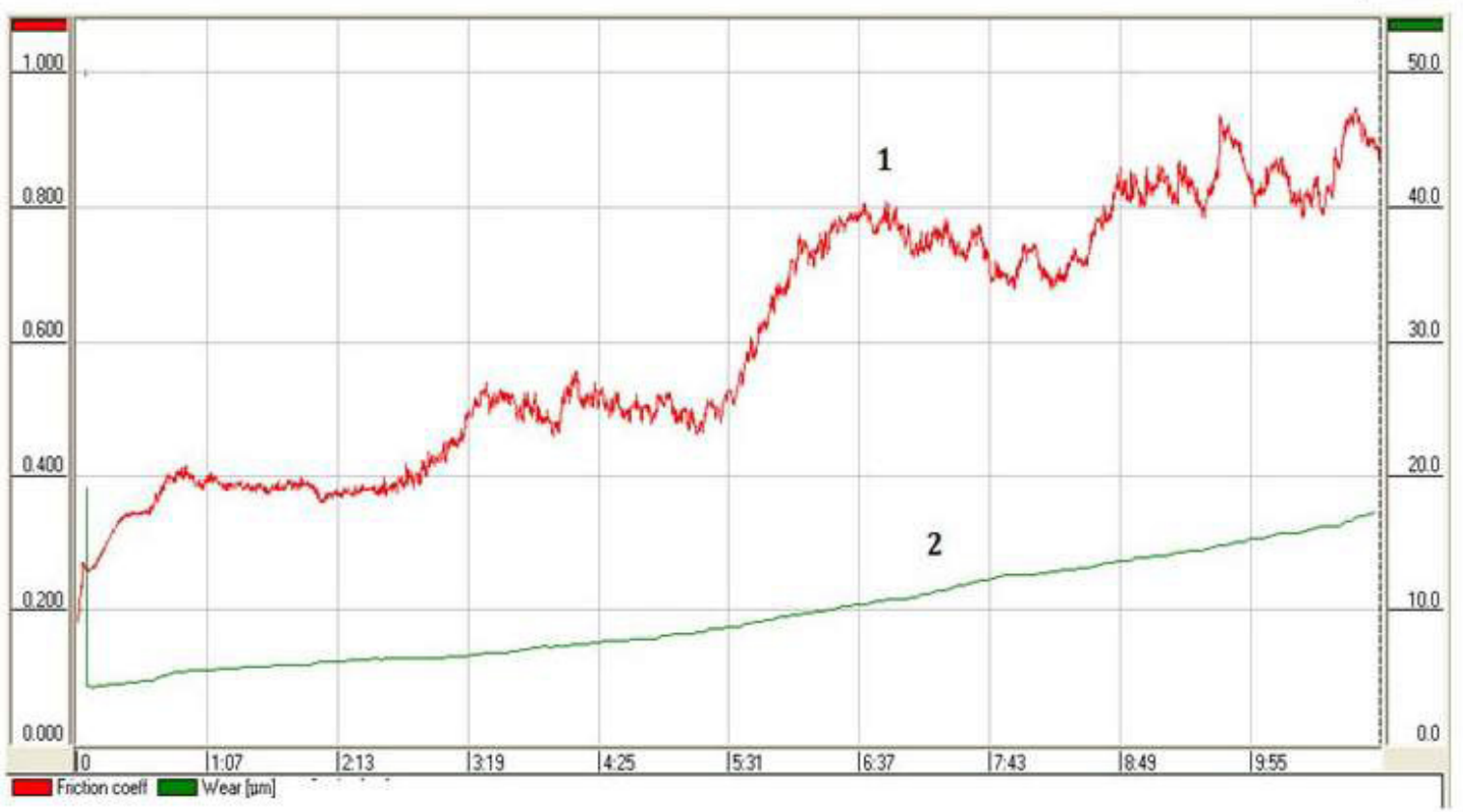

Pис. 4. (Color online) Трибограмма образца после силицирования: 1 - коэффициент трения, 2 - износ.

Fig. 4. (Color online) Tribogram of sample after siliconizing: 1 - coefficient of friction, 2 - wear.

coeff. of friction

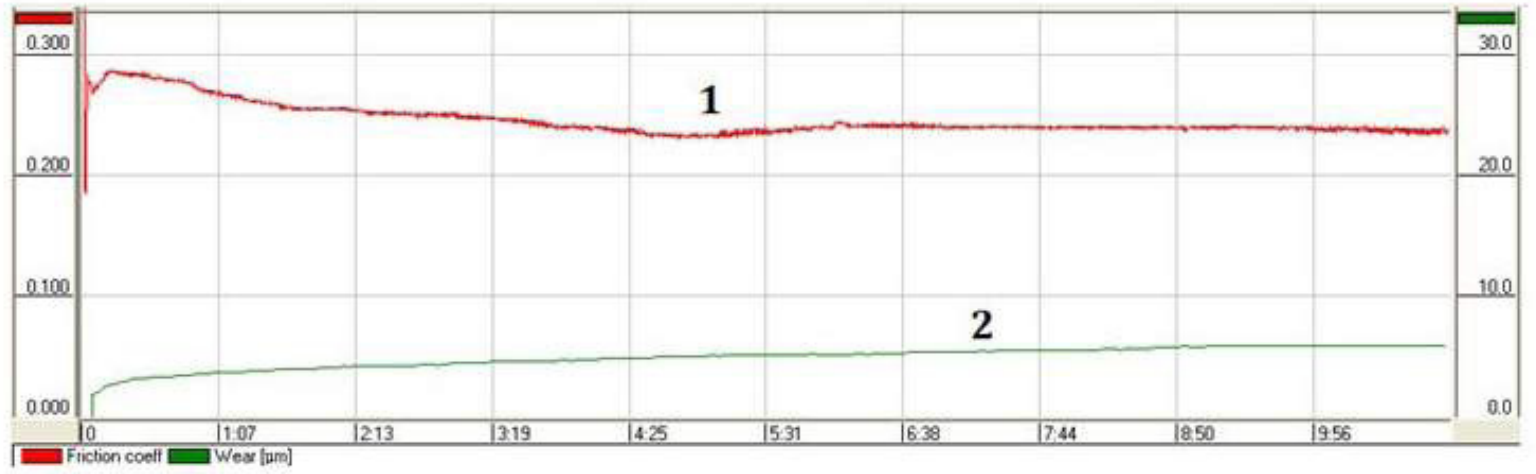

Puc. 5. (Color online) Трибограмма наводороженного образца после азотонауглероживания: 1 - коэффициент трения, 2 - износ. Fig. 5. (Color online) Tribogram of a hydrogenated sample after nitrocarburizing: 1 - coefficient of friction, $2-$ wear.

\section{4. Заключение}

Таким образом, наводороживание поверхности образцов приводит к снижению коэффициента трения и износа в процессе испытаний на фреттинг-изнашивание.

Такое поведение наводороженных образцов может объясняться тем, что помимо образования хрупкой гидридной фазы, в них присутствует водород в виде твердого раствора. Сформированный на поверхности образцов циркониевого сплава Э125 гидридный слой характеризуется неравномерным распределением твердости и содержания водорода по толщине. Кроме того холодная деформация увеличивает растворимость водорода в сплавах циркония.
Металлографический анализ образца после силицирования показал наличие нескольких слоев на поверхности. Толщина многослойного покрытия образца находилась в диапазоне 20-100 мкм. На оксидированном образце наблюдалась оксидная пленка толщиной 200 мкм. Толщина слоя на силицированном образце составляла 10 мкм.

В паре цирконий-сталь наблюдается преимущественно коррозионно-механический износ с образованием и удалением оксидной пленки. После же истирания защитных покрытий возможны механизмы схватывания с образованием фрикционных связей и дальнейшего разрушения материала.

Полученные модификации поверхности циркониевых образцов позволяют улучшить механические свойства, 
существенно снизить уровень наводороживания, и повысить работоспособность конструкционных элементов, выполненных из циркониевых сплавов.

\section{Литература/References}

1. A. Zielinski, S. Sobieszczyk. International Journal of Hydrogen Energy. 36, 8619 (2011). Crossref

2. K.A. Terrani. Journal of Nuclear Materials. 501, 13 (2018). Crossref

3. J.H. Sung, T.H. Kim, S.S. Kim. Wear. 250, 658 (2001). Crossref

4. E. Alat, A.T. Motta, R. J. Comstock, J.M. Partezana, D. E. Wolfe. Surface and coatings technology. 281, 133 (2015). Crossref

5. A.S. Kuprin, V.A. Belous, V.N. Voevodin, V. V. Bryk, et. al. Voprosy atomnoj nauki i tekhniki. 1 (89), 126 (2014). (in Russian) [А.С. Куприн, В.А. Белоус, В.Н. Воеводин, В.В. Брык, и др. Вопросы атомной науки и техники. 1 (89), 126 (2014).]

6. I.A. Petel $g u z o v$. Voprosy atomnoj nauki i tekhniki. 2 (78), 114 (2012). (in Russian) [И.А. Петельгузов. Вопросы атомной науки и техники. 2 (78), 114 (2012).]

7. R. Van Nieuwenhove, V. Andersson, J. Balak, B. International Symposium on Zirconium in the Nuclear Industry; Hilton Head, SC (United States) (2016) p. 965. Crossref

8. L.V. Selezneva, B.V. Bushmin, Ju.V. Dubrovskij, I. A. Hazov. Voprosy atomnoj nauki i tekhniki. Ser. Termoyadernyj sintez. 2, 108 (2008). (in Russian)
[Л.В. Селезнева, Б.В.Бушмин, Ю.В. Дубровский, И. А. Хазов. Вопросы атомной науки и техники. Сер. Термоядерный синтез. 2, 108 (2008).]

9. K. Barrett, S. Bragg-Sitton, D. Galicki. Advanced LWR Nuclear Fuel Cladding System Development Trade-off Study. Idaho (2012) 34 p.

10. B. R. Maier, B.L. Garcia-Diaz, B. Hauch, L.C. Olson, R. L. Sindelar, K. Sridharan. Journal of Nuclear Materials. 466, 712 (2015). Crossref

11. C. Tang, M. Stueber, H. J. Seifert, M. Steinbrueck. Corrosion reviews. 35 (3), 141 (2017). Crossref

12. J.-Ch. Brachet, I. Idarraga-Trujillo, M. Le Flema, M. Le Saux, et al. Journal of Nuclear Materials. 517, 268 (2019). Crossref

13. H.-G. Kim, I.-H. Kim, Y.-I. Jung, D.-J. Park, et al. Journal of Nuclear Materials. 465, 531 (2015). Crossref

14. Y. Chen, X. Nie, D. O. Northwood. Surface and coatings technology. 205 (6), 1774 (2010). $\underline{\text { Crossref }}$

15. P. Lai, H. Zhang, L. Zhang, Q. Zeng, J. Lu, X. Guo. Wear. 424-425, 53 (2019). $\underline{\text { Crossref }}$

16. C. Lorenzo-Martin, O.O. Ajayi, K. Hartman, S. Bhattacharya, A. Yacout. Wear. 426-427 (A), 219 (2019). Crossref

17. I.P. Chernov, E.V. Berezneeva, N.S. Pushilina, V.N. Kudiyarov, et. al. Technical Physics. 60 (2), 260 (2015). Crossref

18. G. C. Lee, H. Noh, H. Yeom, H. Jo, T.K. Kim, M. Kim, K. Sridharan, H.S. Park. Annals of nuclear energy. 126, 350 (2019). $\underline{\text { Crossref }}$ 